Journal of Pacific Rim

Psychology

www.cambridge.org/prp

\section{Original Article}

Cite this article: Pattison E. and Davidson G.R. (2019). The role of perceived threat in Australians' endorsement of asylum-seeker policies. Journal of Pacific Rim Psychology, Volume 13, e21. https://doi.org/10.1017/ prp.2019.13

Received: 16 September 2018

Revised: 20 March 2019

Accepted: 21 March 2019

Keywords:

asylum seeker; government policy; integrated threat theory; attitudes

Author for correspondence: Emily Pattison, Email: emilyclairepattison@gmail.com

\section{The role of perceived threat in Australians' endorsement of asylum-seeker policies}

\author{
Emily Pattison and Graham R. Davidson
}

School of Health and Life Sciences (Psychology), Federation University Australia, Victoria, Australia

\section{Abstract}

Australia's treatment of asylum seekers continues to polarise public debate. The present study sought to investigate the factors that may influence an individual's endorsement of deterrencebased government policies. Using the integrated threat theory of prejudice, the present study examined the role of perceived threat in shaping Australian voters' political attitudes toward asylum seekers. A total of 255 Australian citizens completed an online questionnaire that assessed their support for aspects of government policy and their perceptions of asylum seekers as a threat. Hierarchical multiple regression analyses were used to examine the combined and unique influences of perceived threat and sociodemographic factors on overall and individual government policy endorsement. Results indicated that various types of threat (realistic, symbolic, and negative stereotypes) were significant predictors of policy support. Practical implications regarding the development of anti-discriminatory strategies and directions for future research are discussed.

The right to seek asylum in Australia is a key political issue that continues to garner significant attention and debate. An asylum seeker is "an individual who has sought international protection and whose claim for refugee status has not yet been determined" (United Nations High Commissioner for Refugees [UNHCR], 2009, p. 35). As a voluntary signatory to the 1951 Refugee Convention relating to the Status of Refugees as amended by the 1967 Protocol (UNHCR, 2011), Australia has an international responsibility to provide protection to asylum seekers and refugees, and process their claims. Relative to the rest of the world, Australia hosts only a small proportion of those seeking protection. Global refugee intake measures rank Australia $20^{\text {th }}$ overall, accounting for only $0.65 \%$ of the world's refugees and asylum seekers (Refugee Council of Australia, 2017). Despite having a relatively small intake, the Australian government's stance toward the unprompted arrival of asylum seekers is recognized as being significantly tougher and more punitive than other Western countries (Haslam \& Holland, 2012).

Successive Australian governments have framed asylum seekers as a threat to the nation and have consequently implemented harsh policies characterized as "border protection" (Hartley \& Pedersen, 2007). Current legislation receives bipartisan support from the two main political parties and aims to deter individuals from seeking protection in Australia. These policies include: Operation Sovereign Borders (OSB), an initiative implemented by the Liberal-National Coalition to combat people smuggling and stop the entry of asylum boats into Australian waters (Liberal Party of Australia, 2013); indefinite offshore detention and processing; placement of child asylum seekers in mandatory detention; provision of temporary protection visas for asylum seekers; and compulsory third country resettlement of asylum seekers who are judged to be genuine refugees.

\title{
Policy implications
}

The implications of Australian asylum-seeker policies have been the subject of widespread condemnation and concern for advocacy groups, human rights bodies and health professionals. In particular, the prolonged and indefinite nature of detention has raised serious concerns and prompted a body of psychological research on the severe and lasting effects (Newman, 2013; Robjant, Hassan, \& Katona, 2009). An Australian evidence-based review concluded that both mandatory detention and temporary protection visas have detrimental effects on refugee mental health and well-being (Davidson, Murray, \& Schweitzer, 2008). In one cited study, it was estimated that men's and women's rates of suicidal behavior in Australian detention centres were approximately 41 and 26 times the national average respectively (Dudley, 2003). More recent reports from International Health and Medical Services (IHMS, 2015) offer no indication of any improvement, with two offshore asylum seekers being placed under surveillance for suicide or self-harm every three days (Doherty, 2016). Alarmingly, the time asylum seekers are held in 
immigration detention centers reached a record high under the government of the day, and continues to increase at a steady rate (Hasham, 2016). The latest figures from the Department of Immigration and Border Protection (DIBP) reveal that, as of April 2018, people had been held in detention facilities for an average of 434 days (DIBP, 2018).

\section{Australian attitudes toward government policies}

Asylum-seeker policies consistently polarise public opinion in Australia. The negative implications of these policies have been researched and documented extensively in the media. Reports of riots, hunger strikes and self-harm in offshore processing centers have sparked public outcry and concern. In a qualitative study by Muller (2016), participants in 10 focus group discussions expressed sincere humanitarian concerns over the treatment of asylum seekers but they could not identify alternative policies that would maintain the protection of Australia's borders. Despite receiving some backlash, the government's tough approach toward asylum seekers and refugees consistently receives a high level of public support (see Markus \& Arunachalam, 2018). In 2015, the Mapping Social Cohesion report employed a nationally representative sample of 1500 respondents in order to gauge public attitudes on issues such as asylum-seeker policy (Markus, 2015). The findings showed that voters with strongly negative views toward asylum seekers outnumbered those with strongly positive views by more than two to one, as reflected by the $41 \%$ of respondents who agreed that boats should be turned back and arrivals should be detained (Markus, 2015). Driven by the public indifference to the plight of asylum seekers and refugees, the general aim of this study is to understand the factors that may influence Australians' endorsement of government policy on border protection.

\section{Threat}

A large body of empirical evidence has identified threat as a strong predictor of prejudice toward outgroups (Bizman \& Yinon, 2001; Stephan \& Stephan, 1996). Researchers argue that when members of a dominant culture feel threatened by a minority group, they are less likely to be receptive toward them (Croucher, 2013; Dandy \& $\mathrm{Pe}-\mathrm{Pau}, 2010)$. The association between asylum seekers and threats posed to the ingroup has been well established in previous discourse analysis studies. In an analysis of Australian print media, Saxton (2003) found that terms such as "threatening" and "illegal" were used frequently to describe asylum seekers in a negative light. These unfavorable constructions served to instil a sense of fear into the public and reinforce the exclusionary national discourse. Similarly, Klocker and Dunn (2003) analyzed government media releases and found that the term "threat" was the third most commonly used description of asylum seekers. They suggested that concurrent references to border security and Australia's sovereignty were employed by the government to legitimize and justify their strict policies as an act of national interest.

Based on this previous research, one may question whether Australians' endorsement of deterrence-based policies is influenced by a perception of asylum seekers as a threat. It has been argued that people's feelings and perceived threats toward a social group predict their attitudes toward their relevant policies (Cottrell, Richards, \& Nichols, 2010). A recent study revealed a mediating effect of threat perceptions on the relationship between asylum-seeker policy endorsement and political ideology in Israel and Australia (Canetti, Snider, Pedersen, \& Hall, 2016). Additionally, their results indicated that, in both contexts, there was a strong correlation between exclusionary policy attitudes and perceptions of threat.

To examine the role of threat in public attitudes toward asylumseeker government policy, the present research adopted a theoretical framework known as the integrated threat theory (ITT) of prejudice. Developed by Stephan and Stephan (2000), the theory asserts that there are four basic types of threat posed by outgroups that lead to intergroup prejudicial relations: realistic threats, symbolic threats, intergroup anxiety, and negative stereotypes. By making this distinction, the theory allows for comparisons to be made about the relative influence of each threat component on prejudice. The researchers emphasized that it is the perception of these threats alone that plays a causal role in prejudice, irrespective of whether or not the threat is real (Stephan \& Stephan, 1996). Stephan and colleagues have applied ITT to a variety of intergroup contexts, and have demonstrated that perceived threats are good predictors of attitudes toward immigrants (Stephan, Ybarra, Martnez, Schwarzwald, \& Tur-Kaspa, 1998), women's attitudes toward men (Stephan, Stephan, Demitrakis, Yamada, \& Clason, 2000), intercultural attitudes (Stephan, Diaz-Loving, \& Duran, 2000), and attitudes toward people living with cancer or HIV/ AIDS (Berrenberg, Finlay, Stephan, \& Stephan, 2002). Additionally, a meta-analysis of the intergroup threat literature provided support for the overall validity of ITT. The analysis involved 95 samples, from which it was concluded that ITT was a useful and viable framework for researchers to use (Riek, Mania, \& Gaertner, 2006). The results also indicated that all four threat variables of ITT were significant and unique predictors of outgroup attitudes (Riek et al., 2006).

Realistic threat encompasses any threat to the well-being of the ingroup or its members (Stephan \& Stephan, 2000). More specifically, such threats pertain to "the outgroup endangering the existence, political or economic power, or physical wellbeing of the ingroup" (Bizman \& Yinon, 2001, p. 191). It is important to note that the term "realistic" does not mean that these threats are feasible or grounded in reality. Rather, the purpose of the adjective is to denote perceptions of tangible and quantifiable resources. These may include preferential access to public housing and government assistance, competition for employment, threats to national security, and a general burden on the Australian taxpayer (Muller, 2016). Several studies have identified realistic threat as a robust predictor of prejudice toward outgroups (Pereira, Vala, \& Costa-Lopes, 2010; Suhnan, Pedersen, \& Hartley, 2012). Using an Australian sample of 261 university students, Schweitzer and colleagues assessed the predictive value of realistic and symbolic threat on attitudes toward refugees (Schweitzer, Perkoulidis, Krome, Ludlow, \& Ryan, 2005). The results revealed that realistic threat was the strongest predictor of refugee prejudice and support for stricter border control, although symbolic threat was still significantly predictive of unfavourable attitudes (Schweitzer et al., 2005). Similar results were found in the American context. Murray and Marx (2013) assessed attitudes toward immigrants and refugees in the United States and found that higher realistic threat scores were significant predictors of prejudicial attitudes. A recent Australian meta-analysis investigated prejudice-relevant correlates of attitudes toward refugees and asylum seekers (Cowling, Anderson, \& Ferguson, 2019). In line with previous studies, the findings revealed that perceived symbolic and realistic threats were the strongest correlates of refugee prejudice.

Symbolic threat pertains to perceived group differences in values, beliefs, morals, standards, and attitudes (Stephan \& Stephan, 2000). It occurs when members of an ingroup feel that their culture 
or system of values is being undermined by an outgroup. In the Australian context, qualitative analyses have provided insight into the particular types of symbolic threats that asylum seekers are perceived to pose. In their study assessing attitudes toward asylum seeker and refugee policies, Hartley and Pedersen (2015) found participants were largely concerned that new arrivals were unwilling to assimilate into society. Concerns about a lack of assimilation resonated with participants in Muller's (2016) focus group discussions. However, the most significant finding was the prevalence of disquiet about the "Islamization" of Australia. That is, there was a tendency among the sample to perceive asylum seekers as Muslims who seek to impose their religious practices on Australian society (Muller, 2016). Several studies have found symbolic threats to be related to negative attitudes toward an outgroup (Corenblum \& Stephan, 2001; Pereira, Vala, \& Leyens, 2009). One study implemented ITT to examine Dutch adolescents' prejudice toward Muslims (Velasco González, Verkuyten, Weesie, \& Poppe, 2008). The relationship between perceived threat and prejudice was tested using structural equation modeling, with results revealing that higher scores of symbolic threats predicted prejudice toward Muslims (Velasco González et al., 2008).

Intergroup anxiety refers to the anticipation of negative consequences when interacting with members of an outgroup (Stephan \& Stephan, 1985). It involves feelings of discomfort or awkwardness, triggered by an unfamiliarity about how one is expected to behave. Some researchers who have used ITT suggest distinctions should be made between threats to the individual (intergroup anxiety) and threats to the group (realistic threat, symbolic threat, and negative stereotypes; Stephan \& Renfro, 2002). This discrepancy has led previous researchers to exclude intergroup anxiety as a threat variable in their studies (Croucher, 2013). However, Riek and colleagues' (2006) meta-analysis of 95 ITT studies found that intergroup anxiety had the strongest unique relationship of the theory's four components with outgroup attitudes. Given this result, intergroup anxiety was included as a predictor variable in the present study. Social psychological research has established a relationship between intergroup anxiety and prejudicial attitudes toward outgroups. For example, the role of intergroup anxiety has been explored in relation to Indigenous Australians and refugees (Turoy-Smith, Kane, \& Pedersen, 2013). Questionnaires with measures of contact, intergroup anxiety, prejudice, and policy support were sent to 1000 households in Perth. An analysis of the 114 returned questionnaires revealed that lower levels of intergroup anxiety toward Indigenous Australians and refugees were significantly associated with lower levels of prejudice (Turoy-Smith et al., 2013).

Negative stereotypes refer to the negative expectations concerning the attributes and behavior of outgroup members (Stephan \& Stephan, 2000). Despite the fact that asylum seekers are an extremely diverse group of individuals, they tend to be stereotyped as a collective whole (Croston \& Pedersen, 2013). Research conducted by Pedersen and colleagues has shown consistently that members of the public conceptualize asylum seekers as "illegal" "queue jumpers" who must be "cashed up" to pay people smugglers (Pedersen, Attwell, \& Heveli, 2005; Pedersen, Watt, \& Hansen, 2006). Another negative stereotype that has been cited frequently is the tendency to typecast all asylum seekers as Muslim, and then conflate this association with the potential for terrorism (Muller, 2016). Decades of psychological literature have associated stereotypes with prejudice (see Dovidio, Hewstone, Glick, \& Esses, 2010, for a review). Specifically, previous research has demonstrated that negative stereotypes may influence people's attitudes toward asylum seekers. A recent Australian study examined the predictive role of false beliefs about asylum seekers in deterrent-based policy endorsement (Hartley, Anderson, \& Pedersen, 2018). The results of their multiple hierarchical regression models indicated that endorsement of false beliefs (such as asylum seekers as "queue jumpers") was the strongest predictor of policy support.

\section{Sociodemographic factors}

The research discussed has explored the social psychological antecedents of negative attitudes toward outgroups. Notwithstanding, several studies have also identified a number of sociodemographic variables thought to be linked with prejudice (see Anderson \& Ferguson, 2017). Anderson (2016) found that gender was an important predictor of both explicit and implicit attitudes toward asylum seekers. Males have been found to hold more negative attitudes toward asylum seekers and refugees than do females (Anderson, 2016; Pedersen et al., 2005), and are more likely to justify the harsh treatment of asylum seekers by means of morally disengaging with them (Greenhalgh, Watt, \& Schutte, 2015). Negative attitudes toward minority groups have also been shown to be associated with level of education attained. People with lower levels of formal education have been found to hold harsher views on asylum seekers (Greenhalgh et al., 2015; Suhnan et al., 2012). Conversely, people who held disapproving views of government policy were among the more highly educated (Muller, 2016). In line with these findings, Cowling et al. (2019) meta-analyzed 70 relevant studies and found that being male and less educated were associated with negative attitudes toward refugees and asylum seekers. Research has also identified age as a correlate of attitude. During the 2013 Australian federal election, older voters were much more likely to believe restrictions on temporary work visas should be tightened ("Vote Compass", 2013). Moreover, Muller (2016) found that participants who were appalled by the cruelties of detention centres were primarily younger respondents. Finally, there is some evidence to suggest that Australians living in rural and outer-metropolitan areas hold more hostile views toward immigrants, and most likely toward asylum seekers as well (Goot \& Watson, 2005).

\section{Aims and hypotheses}

In the context of asylum seekers and refugees, successive Australian governments have implemented deterrence-based policies that have been shown to cause severe human suffering. Notwithstanding, these policies receive active support from Australian voters. Research into the public's policy attitudes is therefore necessary as it could influence the maintenance or modification of harmful government policies. Additionally, information about the factors underlying voter attitudes may inform public debate on a highly contentious issue in Australian politics.

The asylum-seeker and refugee policies mentioned previously have bipartisan support from the two main political parties. That is, support for the policies may be independent of the party for which a person votes. Therefore, the present study sought to examine the factors that may influence an individual's support for punitive and restrictive government policies. ITT asserts that realistic threat, symbolic threat, intergroup anxiety, and negative stereotypes all contribute to the formation of prejudicial attitudes toward outgroups. This research aimed to contribute to the intergroup literature by exploring the antecedents of Australian government policy endorsement, with a specific focus on the predictive role of threat in an Australian sample. It also aimed to understand 
whether age, gender, level of education, or place of residence influence public support for government policy. Based on a review of the literature, it was hypothesized that (a) Australian voters who reported high levels of realistic threat, symbolic threat, intergroup anxiety, and negative stereotypes would be more likely to endorse the government's policy on asylum seekers; and (b) Australian voters who were older, male, had less formal education, or lived in rural regions would be more likely to endorse asylum-seeker policy.

\section{Method}

\section{Participants}

The sample consisted of 255 Australian citizens (137 females, 113 males, and 5 who identified as other) who were eligible to vote. Ages ranged from 18 to 74 years, with a mean age of 30.68 $(S D=13.04)$ years. The majority of participants lived in inner metropolitan areas of Australia (72.2\%). The remaining participants lived in outer metropolitan areas (16.5\%) and regional areas (11.4\%). Overall, a majority of the sample had attended university, with $49.8 \%$ indicating they had a bachelor degree and $27.8 \%$ a postgraduate degree. A further $10.6 \%$ had attained a vocational diploma, while $11.8 \%$ reported high school as their highest level of education.

\section{Materials}

A questionnaire was designed to assess individuals' perceptions of threat and attitudes toward asylum seekers. The questionnaire consisted of six sections. The first section measured individuals' endorsement of five government policies regarding asylum seekers. The following four sections measured the four types of perceived threat posited by ITT. Each measure used a 5-point, Likert-type scale response format (see Revilla, Saris, \& Krosnick, 2013 for discussion). The final section of the questionnaire asked participants to provide information about their age, gender, highest level of education obtained, and where they lived.

\section{Endorsement of policy}

In light of government policies constantly changing, there were no existing scales that measure public endorsement of Australia's current punitive asylum seeker policies. Consequently, this study created brief summaries of five pertinent, topical policies, namely indefinite offshore detention and processing of asylum seekers, mandatory detention of child asylum seekers, compulsory third country resettlement arrangements, use of temporary protection visas, and boat turn-backs. These summaries were objective and unbiased, constructed using official government resources from the Department of Immigration and Border Protection (DIBP) and the Liberal Party of Australia. The five items used to measure level of agreement with policies on indefinite offshore detention, mandatory detention of children, third country resettlement, temporary protection visas, and OSD respectively were as follows: (a) "Asylum seekers who arrive by boat without a valid visa are indefinitely detained in offshore processing centres (Nauru or Manus Island). Their claims for protection are assessed under the laws of those third countries"; (b) "In April 2016, the Immigration Minister announced there are no more asylum-seeker children being held in offshore detention centres. However, 50 children still remained on Nauru"; (c) "Asylum seekers in offshore detention will never be resettled in Australia, even if found to be genuine refugees. They have the option to return to their country of origin or be resettled in countries such as Papua New Guinea or Cambodia"; (d) "Asylum seekers without a valid visa are only eligible to apply for a Temporary Protection Visa (TPV) or Safe Haven Enterprise Visas (SHEV). Both visas allow work, Centrelink, and Medicare, but deny overseas travel, permanent residency and family reunions"; and (e) "Operation Sovereign Borders is a deterrence-based initiative aimed at stopping the entry of asylum seeker boats to Australia. Military vessels intercept the boats and turn or tow them back to their country of departure". Participants were asked to indicate the extent to which they agreed with each of the policies using a Likert-type scale ranging from 1 (strongly disagree) to 5 (strongly agree). The scale was shown to have acceptable internal consistency in the present study, Cronbach's $\alpha=.93$.

\section{Realistic threat scale}

Perceptions of realistic threat posed by asylum seekers and refugees were measured using the Realistic Threat Scale (Schweitzer et al., 2005). The scale consists of seven items that measure perceived threats to the physical or material welfare of the ingroup. A sample item is: "Refugees have increased the tax burden on Australians". Participants were asked to indicate the extent to which they felt these items reflected their own opinions. To maintain consistency in the design of the questionnaire, the original 10-point scale was adapted to a 5-point Likert-type scale. The scale was shown by Schweitzer et al. (2005) to have acceptable internal consistency, Cronbach's $\alpha=.91$, and in the present study, Cronbach's $\alpha=.91$.

\section{Symbolic threat scale}

Perceptions of symbolic threat posed by asylum seekers and refugees were measured using the Symbolic Threat Scale (Schweitzer et al., 2005). The scale consists of seven items that measure perceived threats to the cultural values, morals, and beliefs of the ingroup. A sample item is: "Refugees should learn to conform to the rules and norms of Australian society as soon as possible after they arrive". Participants were asked to indicate the extent to which they felt these items reflected their opinions on refugees in Australia. The same modification of the response format in the realistic threat scale was used for the symbolic threat scale. Participants responded using a Likert-type scale, ranging from 1 (strongly disagree) to 5 (strongly agree). The scale was shown to have acceptable internal consistency in Schweitzer et al.'s original study, Cronbach's $\alpha=.87$, and in the present study, Cronbach's $\alpha=.92$.

\section{Intergroup anxiety}

Level of perceived intergroup anxiety elicited by asylum seekers was measured using an adapted version of the Intergroup Anxiety Scale (Stephan \& Stephan, 1985). The scale consists of 12 items that measure perceived levels of anxiety when interacting with members of an outgroup. Participants were asked to indicate the extent to which they felt these items reflected how they would feel when interacting with an asylum seeker. A sample item is "Tense". The same modification of the response format in the realistic and symbolic threat scales was used for the intergroup anxiety scale. Participants responded using a Likert-type scale ranging from 1 (not at all) to 5 (extremely). The scale has been shown to have acceptable internal consistency in a study examining attitudes toward affirmative action policies, Cronbach's $\alpha=.93$ (Renfro, Duran, Stephan, \& Clason, 2006), and in the present study, Cronbach's $\alpha=.92$. 


\section{Negative stereotypes}

Endorsement of negative stereotypes relating to asylum seekers was measured using an adapted version of the Stereotypes Scale (Velasco González et al., 2008). The original scale consisted of eight trait adjectives that describe Muslims. Given that both Muslims and asylum seekers are recognized as outgroups, the present study used the same items and replaced "Muslim" with "asylum seeker". Participants were asked to indicate the extent to which they felt these items described asylum seekers coming to Australia. A sample item is "Dishonest". The response format consisted of a Likerttype scale, ranging from 1 (no, absolutely not) to 5 (yes, absolutely). The scale was shown to have acceptable internal consistency in the original study by Velasco González et al. (2008), Cronbach's $\alpha=.83$, and in the present study, Cronbach's $\alpha=.92$.

\section{Sociodemographic factors}

Participants were asked to state their gender (male, female, or other), their age in years, their level of education $(1=$ high school, $2=$ vocational diploma, $3=$ bachelor degree, or $4=$ postgraduate degree), and where they live (measured by postcode). Postcodes were assigned as either $1=$ inner metropolitan, $2=$ outer metropolitan, or $3=$ regional areas according to the Doctor Connect classification scheme (Australian Government Department of Health, n.d.) to measure level of rurality.

\section{Design and analysis}

The present study employed a cross-sectional, correlational survey design to examine the sample's attitudes toward asylum-seeker policies. A series of hierarchical multiple regression analyses with two blocks of predictors was used to investigate the combined and unique influences of perceived threat and sociodemographic factors on government policy endorsement. Perceptions of threat as categorized by ITT (realistic threat, symbolic threat, intergroup anxiety, and negative stereotypes) were entered as predictor variables at step 1; sociodemographic variables (age, gender, level of education, place of residency) were entered as predictor variables at step 2; and endorsement of the five government policies relating to asylum seekers and refugees in total and separately were entered as the criterion variables in each regression analysis. The order of entry of variables was determined by the theoretical importance and explanatory power of each predictor group in relation to the outcome, with the threat variables being accorded priority of entry based on their theoretical significance (see Ho, 2013; Petrocelli, 2003). Entering the variables in this way also allowed for examination of whether the predictive relationship between threat and government policy endorsement was modified by the inclusion of sociodemographic variables. Finally, a multivariate analysis of variance was employed to investigate any gender differences. The probability level was set at $p<.01$ to decrease the likelihood of a type I error.

\section{Procedure}

The research received full ethics approval from Federation University Australia's Human Research Ethic Committee (HREC; Approval \#B16-052). Participants were recruited using convenience sampling and snowball sampling. They were asked to complete an electronic questionnaire consisting of six sections. The link to the questionnaire was shared on social media platforms and online forums where attitudes toward government policy are openly discussed. It was accompanied by an advertisement informing individuals that they must be eligible to vote in Australia if they wished to participate in the survey. Participants received a Plain Language Information Statement that included all necessary information that would allow them to make an informed decision about consent. They were informed that their participation was completely voluntary, and refusal to participate required no explanation. The questionnaire did not require any identifiable information; therefore, all responses were anonymous. Participant consent was implied by the completion and submission of the answers. Participants were informed that the questionnaire would take no longer than 15 minutes to complete.

\section{Results}

The means and standard deviations for the threat scales and policy endorsement scores are presented in Table 1. The individual policy endorsement scores were summed to create an overall policy endorsement score for each participant. Overall, the mean total policy endorsement score was very close to the scale midpoint ( $M=12.24, S D=6.67)$, suggesting that the whole sample neither strongly agreed nor disagreed with government policy. Individual policy scores were also included to see which aspects of current government policy were endorsed more than others. The provision of temporary protection received the most support $(M=2.87, S D=1.37)$. Conversely, mandatory detention of children received the least support $(M=2.17, S D=1.46)$.

\section{Correlations between threat, policy endorsement and sociodemographic variables}

The relationships between measures of threat, measures of government policy endorsement, and sociodemographic variables were investigated using Pearson product-moment correlation coefficients (see Table 1). Preliminary analyses were also performed to ensure that assumptions about normality, linearity, outliers, and multicollinearity were not violated. The assumptions of normality were assessed for each variable, and inspection of histograms and statistics of each of the variables revealed these assumptions were not violated. All four ITT variables were significantly correlated with one another. However, inspection of the variance inflation factors (VIF) suggested that multicollinearity was not a problem, as each value fell well below the threshold of problematic multicollinearity; for example, VIF > 10 (O'Brien, 2007). There was a significant, positive correlation between total government policy endorsement and: realistic threat $(r=.78$, $p<.01)$, symbolic threat $(r=.78, p<.01)$, intergroup anxiety $(r=.39, p<.01)$, and negative stereotypes $(r=.74, p<.01)$, with high levels of perceived threat associated with higher levels of policy endorsement. With regard to the relationship between sociodemographic variables and overall policy endorsement, there was only a significant correlation between total endorsement and gender $(r=-.25, p<.01)$.

\section{Gender differences}

A one-way, between-groups multivariate analysis of variance (MANOVA) was performed to investigate gender differences in perceptions of threat and total government policy endorsement. There was a statistically significant difference between males and females on total policy endorsement and on the four threat variables, $F(5,244)=8.65, p<.01$; Wilk's lambda $=.85$; partial eta squared $=.15$. Inspection of the mean scores showed that males scored higher than females on realistic threat, symbolic threat, negative stereotypes, and total endorsement of government policy. 
Table 1. Means, standard deviations, and correlation matrix of variables

\begin{tabular}{|c|c|c|c|c|c|c|c|c|c|c|c|c|c|c|c|c|c|}
\hline Variable & Mean & $(S D)$ & Range & 1 & 2 & 3 & 4 & 5 & 6 & 7 & 8 & 9 & 10 & 11 & 12 & 13 & 14 \\
\hline 1. Realistic threat & 16.33 & $(7.45)$ & $7-35$ & - & & & & & & & & & & & & & \\
\hline 2. Symbolic threat & 20.40 & $(7.27)$ & $7-35$ & $.84^{\star}$ & - & & & & & & & & & & & & \\
\hline 3. Intergroup anxiety & 25.86 & $(9.31)$ & $12-60$ & $.54^{\star}$ & $.52^{\star}$ & - & & & & & & & & & & & \\
\hline 4. Negative stereotypes & 16.67 & $(7.44)$ & $8-40$ & $.81^{\star}$ & $.80^{\star}$ & $.59^{\star}$ & - & & & & & & & & & & \\
\hline 5. Total endorsement & 12.24 & $(6.67)$ & $5-25$ & $.78^{\star}$ & $.78^{\star}$ & $.39^{\star}$ & $.74^{\star}$ & - & & & & & & & & & \\
\hline 6. Offshore detention & 2.34 & $(1.54)$ & $1-5$ & $.75^{\star}$ & $.74^{\star}$ & $.39^{\star}$ & $.72^{\star}$ & $.94^{\star}$ & - & & & & & & & & \\
\hline 7. Detention of children & 2.17 & $(1.46)$ & $1-5$ & $.64^{\star}$ & $.63^{\star}$ & $.35^{\star}$ & $.61^{\star}$ & $.86^{\star}$ & $.79^{\star}$ & - & & & & & & & \\
\hline 8. Resettlement & 2.27 & $(1.54)$ & $1-5$ & $.74^{\star}$ & $.75^{\star}$ & $.40^{\star}$ & $.71^{\star}$ & $.93^{\star}$ & $.86^{\star}$ & $.74^{\star}$ & - & & & & & & \\
\hline 9. TPVs and SHEVs & 2.87 & $(1.37)$ & $1-5$ & $.52^{\star}$ & $.55^{\star}$ & $.22^{\star}$ & $.48^{\star}$ & $.75^{\star}$ & $.61^{\star}$ & $.52^{\star}$ & $.62^{*}$ & - & & & & & \\
\hline 10. OSB & 2.60 & $(1.37)$ & $1-5$ & $.75^{\star}$ & $.73^{\star}$ & $.36^{\star}$ & $.69^{\star}$ & $.91^{\star}$ & $.84^{\star}$ & $.71^{\star}$ & $.83^{\star}$ & $.56^{\star}$ & & & & & \\
\hline 11. Gender & & & & $-.29^{\star}$ & $-.30^{\star}$ & -.06 & $-.26^{\star}$ & $-.25^{\star}$ & $-.21^{\star}$ & $-.20^{\star}$ & $-.23^{\star}$ & $-.19^{\star}$ & $-.24^{\star}$ & - & & & \\
\hline 12. Age & & & & .07 & .09 & -.04 & .06 & .12 & .09 & .12 & .09 & .08 & ${ }^{\star} .13$ & -.11 & . & & \\
\hline 13. Residence & & & & .03 & .07 & -.00 & -.00 & -.02 & -.03 & .03 & -.03 & -.03 & $\star-.04$ & .00 & 08 & - & \\
\hline 14. Level of education & & & & .07 & .09 & .03 & .06 & .09 & .08 & .07 & .10 & .05 & .09 & .05 & $.13^{\star}$ & -.07 & - \\
\hline
\end{tabular}

Note: TPV $=$ temporary protection visa. $\mathrm{SHEV}=$ safe haven enterprise visa . ${ }^{*} p<.01$.

Table 2. Model summary of hierarchical regression analysis predicting total policy endorsement

\begin{tabular}{|c|c|c|c|c|c|c|c|c|c|}
\hline Model & $R$ & $R^{2}$ & $R^{2}$ ad & $f^{2}$ & $S E$ & $R^{2}$ change & $F$ change & $d f$ & $p$ \\
\hline 1 & .82 & .68 & .67 & 2.13 & 3.82 & .68 & 130.80 & $(4,250)$ & $<.001^{\star}$ \\
\hline 2 & .83 & .68 & .67 & 2.13 & 3.80 & .01 & 1.55 & $(3,247)$ & .203 \\
\hline
\end{tabular}

Note: ${ }^{\star} p<.01$.

\section{Predictors of government policy endorsement}

\section{Total government policy endorsement}

A summary of the hierarchical regression analysis for variables predicting total government policy endorsement is shown in Tables 2 and 3. At step 1, all four threat scales contributed significantly to the regression model, $F(4,250)=130.80, p<.01$, and accounted for $67.7 \%$ of the variance in total government policy endorsement. The addition of residence, education and age at step 2 explained only an additional $0.6 \%$ of the variance in government policy endorsement, and this change in $R^{2}$ was not significant, $F(7$, $247)=75.90, p=.203$. When all seven independent variables were included in the final model, only realistic threat, symbolic threat, and negative stereotypes were significant predictors of total government policy endorsement. Effect sizes in the form of Cohen's $f^{2}$ for both steps were in the very high range.

\section{Offshore detention and processing}

At step 1, the four threat scales accounted for $62.3 \%$ of the total variance in endorsement of offshore detention and processing, $F(4,250)=103.07, p<.01$. Realistic threat, symbolic threat, and negative stereotypes were all significant predictors of endorsement. The addition of residence, education, and age at step 2 explained only an additional $0.4 \%$ of the variance in support for offshore detention and processing, and this change in $R^{2}$ was not significant, $F(7,247)=59.27, p=.417$. Cohen's $f^{2}=1.63$ for both steps was in the very high range. When all seven independent variables were included in the final model, only realistic threat $(\beta=.34$, $p<.01)$, symbolic threat $(\beta=.29, p<.01)$, and negative stereotypes $(\beta=.27, p<.01)$ were significant predictors of support for offshore detention and processing.

\section{Mandatory detention of children}

At step 1, the four threat scales accounted for $44.9 \%$ of the total variance in endorsement of mandatory detention of children, $F(4,250)=50.85, p<.01$. At step 1 , realistic threat and symbolic threat were the only significant predictors. The addition of residence, education, and age at step 2 explained only an additional $0.4 \%$ of the variance in support for children in detention, and this change in $R^{2}$ was not significant, $F(7,247)=29.18, p=.612$. Cohen's $f^{2}=0.82$ for both steps were in the very high range. When all seven independent variables were included in the final model, only realistic threat $(\beta=.28, p<.01)$ and symbolic threat $(\beta=.27, p<.01)$ were significant predictors of endorsement of mandatory detention of children.

\section{Third country resettlement arrangements}

The hierarchical multiple regression revealed that at step 1 , the four threat scales accounted for $61.8 \%$ of the total variance in endorsement of third country resettlement arrangements, $F(4$, $250)=101.25, p<.01$. At step 1, realistic threat, symbolic threat, and negative stereotypes all contributed significantly to the 
Table 3. Summary of hierarchical regression analysis for variables predicting total policy endorsement

\begin{tabular}{|c|c|c|c|c|c|}
\hline Predictor variable & $B$ & $S E$ & $\beta$ & $t$ & $p$ \\
\hline \multicolumn{6}{|l|}{ Step 1} \\
\hline Realistic threat & .32 & .07 & .36 & 4.93 & $<.001^{\star}$ \\
\hline Symbolic threat & .32 & .07 & .35 & 4.93 & $<.001^{\star}$ \\
\hline Intergroup anxiety & -.09 & .03 & -.12 & -2.64 & $.009^{\star}$ \\
\hline Neg stereotypes & .21 & .06 & .24 & 3.41 & $.001^{\star}$ \\
\hline \multicolumn{6}{|l|}{ Step 2} \\
\hline Realistic threat & .32 & .07 & .36 & 4.91 & $<.001^{\star}$ \\
\hline Symbolic threat & .33 & .07 & .36 & 4.93 & $<.001^{\star}$ \\
\hline Intergroup anxiety & -.08 & .03 & -.12 & -2.52 & .012 \\
\hline Neg stereotypes & .20 & .06 & .23 & 3.23 & $.001^{\star}$ \\
\hline Residence & -.61 & .36 & -.06 & -1.72 & .086 \\
\hline Education & .07 & .26 & .01 & .28 & .780 \\
\hline Age & .25 & .19 & .04 & 1.30 & .197 \\
\hline
\end{tabular}

Note: ${ }^{\star} p<.01$.

regression model. The addition of residence, education, and age at step 2 explained only an additional $0.6 \%$ of the variance in support for children in detention, and this change in $R^{2}$ was not significant, $F(7,247)=58.66, p=.263$. Cohen's $f^{2}=1.63$ for both steps was in the very high range. When all seven independent variables were included in the final model, only realistic threat $(\beta=.31$, $p<.01)$, symbolic threat $(\beta=.35, p<.01)$, and negative stereotypes $(\beta=.23, p<.01)$ were significant predictors of endorsement of third country resettlement.

\section{Temporary protection visas}

At step 1, the four threat scales accounted for $32.8 \%$ of the total variance in endorsement of temporary protection, $F(4$, $250)=30.51, p<.01$. At step 1 , only symbolic threat contributed significantly to the regression model. The addition of residence, education, and age at step 2 explained only an additional $0.5 \%$ of the variance in support for temporary protection, and this change in $R^{2}$ was not significant, $F(7,247)=17.65, p=.576$. Cohen's $f^{2}=0.37$ for both steps was in the very high range. After accounting for the sociodemographic variables in the final model, only symbolic threat $(\beta=.38, p<.01)$ was a significant predictor of endorsement of temporary protection visas.

\section{Operation Sovereign Borders (OSB)}

At step 1, the four threat scales accounted for $61.3 \%$ of the total variance in endorsement of OSB, $F(4,250)=99.11, p<.01$. At step 1 , realistic threat, symbolic threat, intergroup anxiety, and negative stereotypes were all significant predictors of support for OSB. The addition of residence, education, and age at step 2 only explained an additional $0.9 \%$ of the variance in endorsement for OSB, and this change in $R^{2}$ was not significant, $F(7,247)=58.11, p=.122$. Cohen's $f^{2}=1.63$ for both steps was in the very high range. After accounting for the sociodemographic variables in the final model, realistic threat $(\beta=.41, p<.01)$, symbolic threat $(\beta=.29$, $p<.01)$, intergroup anxiety $(\beta=-.13, p=.01)$, and negative stereotypes $(\beta=.20, p<.01)$ all remained significant predictors of endorsement of OSB.

\section{Discussion}

The aim of the present study was to investigate the antecedents of public endorsement of asylum-seeker policy. Using the integrated threat theory of prejudice (Stephan \& Stephan, 2000), the current research addressed the question about whether Australians' perceptions of threat predict their support for the Australian government's asylum seeker policy. It also examined how sociodemographic factors might influence levels of perceived threat and policy support. Based on a thorough review of the literature, a number of hypotheses were formulated.

The hypothesis that Australian voters who reported higher levels of perceived threat would be more likely to endorse asylumseeker policy was partially supported. As predicted, all four components of threat posited by ITT were significantly correlated with policy endorsement. The strength of correlations between threat components and policies varied as a function of the specific policy in question. The weakest relationship observed for each threat component was for provision of Temporary Protection Visas (TPVs) or Safe Haven Enterprise Visas (SHEVs). Interestingly, this policy was the only one in the questionnaire that pertains to asylum seekers who have already arrived in Australia. All other policies described in this study have been implemented by the government to prevent asylum seekers from arriving in Australia. Therefore, it appears as though correlations between policy and threat are stronger when the policy described is deterrence-based. Additionally, realistic threat, symbolic threat, and negative stereotypes were all significant predictors of overall support for government policy. However, after sociodemographic factors were added into the final regression model, intergroup anxiety was not a significant predictor. The predictive validity of each threat variable varied when individual policies were considered separately.

It was also hypothesized that Australian voters who were older, male, had less formal education, and lived in rural regions would feel more threatened by the arrival of asylum seekers, and consequently be more supportive of the government's policies. The findings only provided partial support for the predicted relationship between sociodemographic factors and asylum-seeker policy endorsement. As hypothesized, there were significant gender 
differences in policy support and perceptions of threat. Males scored significantly higher than females on all measures of threat other than intergroup anxiety, and showed greater support for overall and individual government policies. However, contrary to expectation, neither age nor education, nor residency, were significant predictors of asylum-seeker policy endorsement.

The relationship between perceived threat and Australians' attitudes toward asylum-seeker policy has been examined previously. However, there is an absence of research examining the individual roles of threats outlined in ITT (Stephan \& Stephan, 2000). The present study is unique in that it is the first to investigate all four aspects of ITT that predict endorsement of asylum-seeker policies in an Australian context. Additionally, studies examining policy attitudes often include one dependent measure that asks participants whether they agree with the government's overall stance on an issue (e.g. Canetti et al., 2016). In contrast, the present study examines in much greater detail participants' endorsement of specific aspects of the government's asylum-seeker policies and their specific predictors.

\section{ITT as predictors of policy endorsement}

The results contribute to the intergroup literature by providing support for ITT and its ability to predict attitudes toward asylum seeker policy. The combination of realistic threats, symbolic threats, intergroup anxiety, and negative stereotypes accounted for a substantial proportion of the variance in participants' support for the Australian government's treatment of asylum seekers and refugees. The unique predictive validity of each of the threat variables is now discussed.

As hypothesized, perceived realistic threat was significantly related to attitudes toward asylum-seeker policy. Participants who reported higher levels of realistic threat posed by asylum seekers were more likely to endorse asylum policy. Participants who expressed higher levels of realistic threat felt refugees were displacing Australian workers from their jobs, lessening the quality of social services, receiving preferential access to subsidized housing and utilities, and generally taking more from Australia than they were willing to contribute. The results of the hierarchical multiple regression analyses revealed that realistic threat was the strongest ITT predictor of attitudes toward asylum-seeker policies, followed closely by symbolic threat. These findings corroborate those of Schweitzer et al. (2005) and Cowling et al. (2019), who found that realistic threat and symbolic threat were both significant predictors of prejudicial attitudes toward refugees, but that realistic threat was the stronger of the two.

When each of the policies was considered separately, realistic threat was a significant predictor of attitudes toward mandatory offshore detention and processing, placement of children in mandatory detention, compulsory third country resettlement and OSB, after sociodemographic factors had been accounted for. Interestingly, realistic threat was not a significant predictor of attitudes toward temporary protection visas. This result is surprising, given that the provision of TPVs enables asylum seekers to gain access to the very services that participants felt were under threat (such as employment, Centrelink benefits, and Medicare). One possible explanation is that almost one-quarter of participants marked their support for this policy as "neutral", which may be indicative of an uncertainty about what the policy actually means.

As hypothesized, symbolic threat was a significant predictor of endorsement of the government's asylum policy. Participants who reported higher levels of perceived symbolic threat were more likely to be supportive of the government's exclusionary policies toward asylum seekers and refugees. These results corroborate those of Cifti (2012), who found that participants who perceived Muslims as divergent from the mainstream society were more likely to hold unfavorable attitudes toward them. Similarly, results from the hierarchical multiple regression analyses confirmed that perceived symbolic threat was a significant predictor of all six dependent variables. One possible explanation for the strength of symbolic threat as a significant predictor can be drawn from the depictions of asylum seekers to which members of the public are exposed. As previous studies have shown, the Australian media and federal government have collectively framed asylum seekers as the "other", whose entry into the country poses a threat to the national identity (Klocker \& Dunn, 2003; Lueck, Due, \& Augoustinos, 2015). By emphasizing differences rather than commonalities, voters may be more willing to endorse the exclusionary policies that safeguard the values, norms, and beliefs of many Australians.

It should also be noted that out of the four types of threat framed by ITT, perceived symbolic threat had the highest mean score among the sample. That is, individuals in the present study had the strongest concerns about the incompatibility of the values and beliefs of refugees with those of the Australian public. In fact, over two-thirds of the sample either disagreed or strongly disagreed with the statement that refugees should not have to accept Australian ways. These findings are consistent with previous studies investigating attitudes toward asylum seekers (Hartley \& Pedersen, 2015; Muller, 2016), which have all found that for many voters, assimilation is considered to be a requirement of individuals seeking asylum in Australia.

In the present study, intergroup anxiety scores were a representation of how anxious participants would feel when interacting with an asylum seeker. There were significant, positive correlations between intergroup anxiety and each of the policies; however, this significant relationship was not found when intergroup anxiety was entered as a predictor in the regression model. Contrary to what was hypothesized, the results showed that intergroup anxiety was not a significant predictor of overall policy endorsement. Once sociodemographic factors had been accounted for, the regression analyses of each of the individual government policies revealed that intergroup anxiety was only a significant predictor of support for OSB.

These results were inconsistent with past research. In their meta-analytic review, Riek et al. (2006) found that intergroup anxiety had the strongest unique relationship with attitudes toward outgroups. Similarly, a number of correlational studies have found intergroup anxiety to be one of the most consistent predictors of negative attitudes (Bizman \& Yinon, 2001; Corenblum \& Stephan, 2001; Stephan, Renfro, Esses, Stephan, \& Martin, 2005). In contrast, the present findings suggest that intergroup anxiety had the weakest relationship with attitudes toward policies that concern outgroups. These conflicting results may be explained by the context in which studies have measured intergroup anxiety. For example, Islam and Hewstone (1993) found that increased levels of intergroup anxiety were significantly associated with decreased positive attitudes toward outgroup members. However, participants in their study had a considerable degree of contact with the outgroup of interest in everyday life. Conversely, the Australian government's exclusionary policies deny Australians the opportunity to have contact with asylum seekers, thereby making it hard for participants in the present study to gauge how they would feel during an interaction. 
Previous research has also made the distinction between individual level threats (intergroup anxiety) and group-level threats (realistic threat, symbolic threat, negative stereotypes; Croucher, 2013; Stephan \& Renfro, 2002). This discrepancy has led researchers to exclude intergroup anxiety in their application of ITT, and may explain why it was the only non-significant predictor of government policy endorsement out of the four threat variables.

As hypothesized, the results showed that the endorsement of negative stereotypes was significantly related to endorsement of asylum policy. These results are in line with Pedersen et al. (2006), who found a significant correlation between the acceptance of false beliefs and negative attitudes toward asylum seekers. Furthermore, the findings from the regression analyses revealed that once sociodemographic factors were accounted for, negative stereotypes were a significant predictor of support for mandatory offshore processing and detention, mandatory third country resettlement, OSB, and overall policy endorsement. These findings corroborate those of Hartley et al. (2018), who identified endorsement of false beliefs as a strong predictor of Australians' endorsement of offshore processing, community-based processing, and boat turnbacks. While these conceptualizations of asylum seekers are not true, they are prevalent in both the media and political discourse. This becomes problematic, as Australians have very little opportunity to interact with asylum seekers; therefore, negative stereotypes are largely constructed through media exposure (McKay, Thomas, \& Blood, 2011).

Interestingly, endorsement of negative stereotypes was not a significant predictor of support for mandatory detention of child asylum seekers or the provision of temporary protection. One possible explanation for the former is that individuals may only attribute negative stereotypes to adults seeking asylum rather than to children seeking asylum. As a consequence, the endorsement of negative stereotypes may not play a role in the formation of attitudes toward children in detention.

\section{Implications}

The findings of the present research have a number of important implications, all of which can be used to inform public debate on a highly contentious political and social issue. First, they provide insight into the reasons why Australians may support policies that have been documented to cause severe harm to detainees who have sought asylum. The results suggest that individuals endorse these policies because they feel threatened by asylum seekers and refugees. From a theoretical perspective, the findings contribute to the intergroup literature by exploring the predictive validity of threat. The results confirm that realistic threat, symbolic threat, and endorsement of negative stereotypes are all significant predictors of public support for the Australian government's asylum-seeker policies. In a practical sense, these threats may pertain to perceived competition for finite resources (employment, housing, health, and welfare services), newcomers' reluctance to assimilate into Australian culture (discordant values and beliefs), and negative expectations concerning the behavior and attributes of asylum seekers and refugees.

The results suggest that in order to change public attitudes toward exclusionary policies, realistic threat, symbolic threat and negative stereotypes need to be addressed. Consequently, these findings can inform the development of strategies that seek to shift people's mindset of asylum seekers as threats. Advocacy groups and policy makers alike can be guided by this relationship between sources of threat perception and formation of policy attitudes. For example, Renfro et al. (2006) suggested that policy makers might acknowledge the role of threat by phrasing the proposed policies using non-threatening terms. Similarly, Koc and Anderson (2018) suggest that resistance toward acculturation from the receiving community may be overcome by promoting the indispensable benefits of integration and multiculturalism.

The provision of accurate information has also been recognized as an anti-prejudice intervention that seeks to decrease the acceptance of negative stereotypes about an outgroup (Pedersen, Walker, Paradies, \& Guerin, 2011). It is therefore imperative that advocacy groups continue to inform the public about the legality and necessity of seeking asylum and the harmful implications of the Australian government's policies. Similarly, past research has demonstrated how realistic and symbolic threats can be derived from the negative constructions of asylum seekers and refugees in the media and government statements (Klocker \& Dunn, 2003). Given that realistic and symbolic threats were shown to be the strongest predictors of the government's policy endorsement in the present study, it is important that the discourse surrounding asylum seekers and refugees is reframed. Initiatives should be taken to remove the threatening connotations of, and disentangle the link between, asylum seekers and national security. As Haslam and Holland (2012) suggested, the focus instead should be placed on emphasizing the qualities that make asylum seekers human.

Another important implication concerns the development of the policy endorsement scale. Studies thus far have conceptualized attitudes toward asylum seekers or related government policies as one dependent measure. There was an absence of research into the relative support for each of the various aspects of government policy. The notion that individuals could endorse some aspects of government policy but not others was often overlooked. The present study sought to address this issue by including five pertinent aspects of government policy. From a methodological perspective, the scale, which consisted of all five items, had high internal consistency and could be used in future studies to investigate public attitudes toward the government's asylum-seeker policy in general or toward specific aspects of the policy. On a practical level, policy makers can benefit from the present results, as they provide insight into which government policies are endorsed or opposed by the public. In the present sample, the provision of temporary protection received the most support (36.1\%), followed closely by OSB (35.3\%). The policy that received the least support was the incarceration of child asylum seekers $(23.9 \%)$, followed by compulsory third country resettlement $(27.1 \%)$, and offshore processing $(27.9 \%)$.

\section{Limitations and future recommendations}

The findings of the present study and their implications should be interpreted with some limitations in mind. First, the results revealed significant correlations between each of the four threat variables of ITT. While each threat scale had high internal reliability, the significant intercorrelations suggest that realistic threat, symbolic threat, intergroup anxiety, and negative stereotypes may not necessarily be theoretically discrete components. Inspection of the VIF values suggested that multicollinearity was not an issue; however, the relative predictive validity of each threat variable should be interpreted with caution. Finally, the correlational design of the study means that causality between perceptions of threat and endorsement of government policy cannot be assumed. 
A number of recommendations for future research are drawn from the study's limitations. First, the current research yielded significant correlations between the four threat components. These strong intercorrelations have been found in a number of previous studies (e.g. Bizman \& Yinon, 2001; Velasco González et al., 2008). Therefore, more research on the discriminant validity of individual elements of ITT is needed to address whether the theoretical model is comprised of four distinct measures of threat.

As mentioned previously, the symbolic threat of the "Islamization" of Australia has become increasingly prevalent in the asylum-seeker debate (see Muller, 2016). Therefore, future studies may investigate the influence of individuals' religious affiliation on their attitudes toward asylum-seeker policy. Finally, research should consider how broader contextual factors may influence levels of threat and support for government policy. For example, during the time the present research was being conducted, there were a number of terrorist attacks in Western countries. In response to these attacks, the then Immigration Minister and Prime Minister both made public statements about border security that linked asylum seekers with the potential for terrorism. Future studies might look specifically at the threat of terrorism and the role it plays in the formulation of attitudes toward the government's asylum-seeker policy.

\section{Conclusions}

Seeking asylum in Australian is legal and, as a voluntary signatory to the United Nations Refugee Convention, Australia has an obligation to protect individuals fleeing persecution. However, this international obligation is not being met by the government's deterrence-based policies. Detention centers are fostering abuse and self-harm, resettlement options place some refugees in countries that cannot offer protection, and boats are being turned back in dangerous circumstances to countries where asylum seekers face the risk of serious harm. The implications of these policies are detrimental. So, why do they receive bipartisan support from the major political parties and backing from the general public? Using the integrated threat theory of prejudice, the present study sought to address this question by highlighting the role of perceived threat in Australians' endorsement of their government's asylum-seeker policies. The results indicated that realistic threat, symbolic threat, and endorsement of negative stereotypes are all significant predictors of asylum-policy endorsement. In a democratic society like Australia, government policies rely on public endorsement to gain or maintain political power. The current findings have important practical implications that highlight the need to develop strategies that dissociate asylum seekers from the perception of threat. By shifting people's mindsets about asylum seekers and refugees, support for the policies that cause human suffering may be reduced.

\section{References}

Anderson J.R. (2016). Implicit and explicit attitudes toward asylum seekers: Demographic and ideological correlates. Australian Psychologist, 53, 181-191.

Anderson J.R. and Ferguson R. (2017). Demographic and ideological correlates of negative attitudes towards asylum seekers: A meta-analytic review. Australian Journal of Psychology, 70, 18-29.

Australian Government Department of Health. (n.d.). Doctor connect. Retrieved July 28, 2016, from http://www.doctorconnect.gov.au/
Berrenberg J.L., Finlay K.A., Stephan W.G. and Stephan C. (2002). Prejudice toward people with cancer or AIDS: Applying the integrated threat model. Journal of Applied Biobehavioral Research, 7, 75-86.

Bizman A. and Yinon Y. (2001). Intergroup and interpersonal threats as determinants of prejudice: The moderating role of in-group identification. Basic and Applied Social Psychology, 23, 191-196.

Canetti D., Snider K.L., Pedersen A. and Hall B.J. (2016). Threatened or threatening? How ideology shapes asylum seekers' immigration policy attitudes in Israel and Australia. Journal of Refugee Studies, 29, 1-24.

Cifti S. (2012). Islamophobia and threat perceptions: Explaining anti-Muslim sentiment in the West. Journal of Muslim Minority Affairs, 32, 293-309.

Corenblum B. and Stephan W.G. (2001). White fears and native apprehensions: An integrated threat theory approach to intergroup attitudes. Canadian Journal of Behavioural Science/Revue canadienne des sciences $d u$ comportement, 33, 251-268.

Cottrell C.A., Richards D.A. and Nichols A.L. (2010). Predicting policy attitudes from general prejudice versus specific intergroup emotions. Journal of Experimental Social Psychology, 46, 247-254.

Cowling M.M., Anderson J.R. and Ferguson R. (2019). Prejudice-relevant correlates of attitudes towards refugees: A meta-analysis. Journal of Refugee Studies. doi: 10.1093/jrs/fey062

Croston J. and Pedersen A. (2013). "Tell me what I want to hear": Motivated recall and attributions in media regarding asylum seekers. Australian Journal of Psychology, 65, 124-133.

Croucher S.M. (2013). Integrated threat theory and acceptance of immigrant assimilation: An analysis of Muslim immigration in Western Europe. Communication Monographs, 80, 46-62.

Dandy J. and Pe-Pua R. (2010). Attitudes to multiculturalism, immigration and cultural diversity: Comparison of dominant and non-dominant groups in three Australian states. International Journal of Intercultural Relations, 34, $34-46$.

Davidson G.R., Murray K.E. and Schweitzer R. (2008). Review of refugee mental health and wellbeing: Australian perspectives. Australian Psychologist, 43, 160-174.

Department of Immigration and Border Protection. (2018). Immigration detention and community statistics summary 31 January 2018. Retrieved August 9, 2018, from https://www.homeaffairs.gov.au/ReportsandPublications /Documents/statistics/immigration-detention-statistics-31-january-2018.pdf

Doherty B. (2016, March 9). Two offshore asylum seekers placed under suicide or self-harm watch every three days. The Guardian. Retrieved from https:// www.theguardian.com/australia-news/2016/mar/09/two-offshore-asylumseekers-placed-under-suicide-or-self-harm-watch-every-three-days

Dovidio J.F., Hewstone M., Glick P. and Esses V.M. (Eds.). (2010). Prejudice, stereotyping and discrimination: Theoretical and empirical overview. In The SAGE Handbook of Prejudice, Stereotyping and Discrimination (pp. 3-29). Thousand Oaks, CA: Sage Publications.

Dudley M. (2003). Contradictory Australian national policies on self-harm and suicide: The case of asylum seekers in mandatory detention. Australasian Psychiatry, 11, S102-S108.

Goot M. and Watson I. (2005). Immigration, multiculturalism and national identity. In S. Wilson, G. Meagher, R. Gibon, D. Denemark, and M. Western (Eds.), Australian social attitudes: The first report (pp. 182-203). Sydney, Australia: UNSW Press.

Greenhalgh E.M., Watt S.E. and Schutte N.S. (2015). Mechanisms of moral disengagement in the endorsement of asylum seeker policies in Australia. Ethics \& Behaviour, 25, 482-499.

Hartley L. and Pedersen A. (2007). Asylum seekers: How attributions and emotion affect Australians' views on mandatory detention of "the other". Australian Journal of Psychology, 59, 119-131.

Hartley L.K. and Pedersen A. (2015). Asylum seekers and resettled refugees in Australia: Predicting social policy attitude from prejudice versus emotion. Journal of Social and Political Psychology, 3, 179-197.

Hartley L.K, Anderson J.R. and Pedersen A. (2018). Process in the community, detain offshore or 'turn back the boats'? Predicting Australian asylum-seeker policy support from false beliefs, prejudice and political ideology. Journal of Refugee Studies, fey048. doi: 10.1093/jrs/fey048 
Hasham N. (2016, January 12). Asylum seeker detention times blow out to record levels under Malcolm Turnbull. Sydney Morning Herald. Retrieved from http://www.smh.com.au/federal-politics/political-news/asylum-seeker-deten tion-times-blow-out-to-record-levels-under-malcolm-turnbull-20160112-gm 41v7.html

Haslam N. and Holland E. (2012). Attitudes towards asylum seekers: The Australian experience. In D. Bretherton and N. Balvin (Eds.), Peace psychology in Australia (pp. 107-120). New York, NY: Springer.

Ho R. (2013). Handbook of Univariate and multivariate data analysis with IBM SPSS. Danvers, MA: Chapman and Hall.

International Health and Medical Services (IHMS). (2015). Immigration detention health report. July-September 2015 Quarter 3. Retrieved March 25, 2016, from https://uploads.guim.co.uk/2016/03/08/q3_q4_2015.pdf

Islam M.R. and Hewstone M. (1993). Dimensions of contact as predictors of intergroup anxiety, perceived out-group variability, and out-group attitude: An integrative model. Personality and Social Psychology Bulletin, 19, $700-710$.

Klocker N. and Dunn K. (2003). Who's driving the asylum debate? Newspaper and government representations of asylum seekers. Media International Australia Incorporating Culture and Policy, 109, 71-92.

Koc Y. and Anderson J.R. (2018). Social distance toward Syrian refugees: The role of intergroup anxiety in facilitating positive relations. Journal of Social Issues, 74, 790-811.

Liberal Party of Australia. (2013). The Coalition's Operation Sovereign Borders Policy. Retrieved April 18, 2016, from http://sievx.com/articles/ OSB/201307xxTheCoalitionsOSBPolicy.pdf

Lueck K., Due C. and Augoustinos M. (2015). Neoliberalism and nationalism: Representations of asylum seekers in the Australian mainstream news media. Discourse \& Society, 26, 608-629.

McKay F.H., Thomas S.L. and Warwick Blood R. (2011). "Any one of these boat people could be a terrorist for all we know!” Media representations and public perceptions of "boat people" arrivals in Australia. Journalism, 12, 607-626.

Markus A. (2015). Mapping social cohesion. The Scanlon Foundation Surveys 2015. Retrieved April 3, 2016 from http://scanlonfoundation.org.au/wpcontent/uploads/2015/10/2015-Mapping-Social-Cohesion-Report.pdf

Markus A. and Arunachalam D. (2018). Australian public opinion on asylum. Migration and Development, 7, 435-447.

Muller D. (2016). \{Islamisation" and other anxieties: Voter attitudes to asylum seekers. Retrieved April 19, 2016 from http://www.socialequity.unimelb.edu. au/reports/

Murray K.E. and Marx D.M. (2013). Attitudes toward unauthorized immigrants, authorized immigrants, and refugees. Cultural Diversity and Ethnic Minority Psychology, 19, 332-341.

Newman L. (2013). Seeking asylum- Trauma, mental health, and human rights: An Australian perspective. Journal of Trauma \& Dissociation, 14, 213-223.

O'Brien R.M. (2007). A caution regarding rules of thumb for variance inflation factors. Quality \& Quantity, 41, 673-690.

Pedersen A., Attwell J. and Heveli D. (2005). Prediction of negative attitudes toward Australian asylum seekers: False beliefs, nationalism, and self-esteem. Australian Journal of Psychology, 57, 148-160.

Pedersen A., Walker I., Paradies Y. and Guerin B. (2011). How to cook rice: A review of ingredients for teaching anti-prejudice. Australian Psychologist, 46, 55-63.

Pedersen A., Watt S. and Hansen S. (2006). The role of false beliefs in the community's and the federal government's attitudes toward Australian asylum seekers. Australian Journal of Social Issues, 41, 105-140.

Pereira C., Vala J. and Costa-Lopes R. (2010). From prejudice to discrimination: The legitimizing role of perceived threat in discrimination against immigrants. European Journal of Social Psychology, 40, 1231-1250.

Pereira C., Vala J. and Leyens J.P. (2009). From infra-humanization to discrimination: The mediation of symbolic threat needs egalitarian norms. Journal of Experimental Social Psychology, 45, 336-344.

Petrocelli J.V. (2003). Hierarchical multiple regression in counseling research: Common problems and possible remedies. Measurement and Evaluation in Counselling Development, 36, 9-22.
Refugee Council of Australia. (2017). UNHCR Global Trends 2017- How Australia compares with the world. Retrieved August 9, 2018, from https:// www.refugeecouncil.org.au/getfacts/statistics/intl/global-trends-2017/

Renfro C., Duran A., Stephan W.G. and Clason D.L. (2006). The role of threat in attitudes toward affirmative action and its beneficiaries. Journal of Applied Social Psychology, 36, 41-74.

Revilla M.A., Saris W.E. and Krosnick J.A. (2013). Choosing the number of categories in agree-disagree scales. Sociological Methods \& Research, 43, 73-97.

Riek B.M., Mania E.W. and Gartner S.L. (2006). Intergroup threat and outgroup attitudes: A meta-analytic review. Personality and Social Psychology Review, 10, 336-353.

Robjant K., Hassan R. and Katona C. (2009). Mental health implications of detaining asylum seekers: systematic review. The British Journal of Psychiatry, 194, 306-312.

Saxton A. (2003). 'I certainly don't want people like that here': The discursive construction of 'asylum seekers'. Media International Australia incorporating Culture and Policy, 109, 109-120.

Schweitzer R., Perkoulidis S., Krome S., Ludlow C. and Ryan M. (2005). Attitudes towards refugees: The dark side of prejudice in Australia. Australian Journal of Psychology, 57, 170-179.

Stephan W.G. and Renfro C.L. (2002). The role of threat in intergroup relations. In D. Mackie, and E.R. Smith (Eds.), From Prejudice to Intergroup Emotions (pp. 191-208). New York, NY: Psychology Press.

Stephan W.G. and Stephan C.W. (1985). Intergroup anxiety. Journal of Social Issues, 41, 157-175.

Stephan W.G. and Stephan C.W. (1996). Predicting prejudice. International Journal of Intercultural Relations, 20, 409-426.

Stephan W.G. and Stephan C.W. (2000). An integrated threat theory of prejudice. In S. Oskamp (Ed.), Reducing Prejudice and Discrimination: The Claremont Symposium on Applied Social Psychology (pp. 23-45). Mahwah, NJ: Lawrence Erlbaum Associates.

Stephan W.G., Diaz-Loving R. and Duran A. (2000). Integrated threat theory and intercultural attitudes Mexico and the United States. Journal of CrossCultural Psychology, 31, 240-249.

Stephan W.G., Renfro C.L., Esses V.M., Stephan C.W. and Martin T. (2005). The effects of feeling threatened on attitudes toward immigrants. International Journal of Intercultural Relations, 29, 1-19.

Stephan C.W., Stephan W.G., Demitrakis K.M., Yamada A.M. and Clason D.L. (2000). Women's attitudes toward men: An integrated threat theory approach. Psychology of Women Quarterly, 24, 63-73.

Stephan W.G., Ybarra O., Martnez C., Schwarzwald J. and Tur-Kaspa M. (1998). Prejudice toward immigrants to Spain and Israel. An integrated threat theory analysis. Journal of Cross-Cultural Psychology, 29, 559-576.

Suhnan A., Pedersen A. and Hartley L.K. (2012). Re-examining prejudice against asylum seekers in Australia: The role of people smugglers, the perception of threat, and acceptance of false beliefs. The Australian Community Psychologist, 24, 79-97.

Turoy-Smith K.M., Kane R. and Pedersen A. (2013). The willingness of a society to act on behalf of Indigenous Australians and refugees: The role of contact, intergroup anxiety, prejudice, and support for legislative change. Journal of Applied Social Psychology, 43(Suppl. S2), E179-E195.

United Nations High Commissioner for Refugees (UNHC). (2009). Asylum and Refugee Status Determination. Retrieved from http://www.unhcr.org/ 4ce531e09.pdf

United Nations High Commissioner for Refugees (UNHC). (2011). The 1951 Convention Relating to the Status of Refugees and its 1967 Protocol. Retrieved from http://www.unhcr.org/about-us/background/4ec262df9/ 1951-convention-relating-status-refugees-its-1967-protocol.html

Velasco González K., Verkuyten M., Weesie J. and Poppe E. (2008). Prejudice towards Muslims in the Netherlands: Testing integrated threat theory. British Journal of Social Psychology, 47, 667-685.

Vote Compass: Kevin Rudd's asylum seekers policy divides Labor faithful. (2013, August 28). ABC News. Retrieved April 29, 2016, from http:// www.abc.net.au/news/2013-08-21/asylum-seekers-vote-compass-boatsimmigration/4899914 